\title{
The Effect of DOH-PCSI Patient Navigation Access Program for Breast Cancer on Quality of Care at the Medical Oncology Clinic at the Philippine General Hospital: The $1^{\text {st }} 6$ Months
}

\author{
Ma. Pamela D. Patdu, ${ }^{1}$ Wilfredo L. Liangco, ${ }^{1}$ Corazon A. Ngelangel, ${ }^{1,2}$ Anna Melissa S. Guerrero, ${ }^{3}$ \\ Ma. Victoria G. Ala, ${ }^{3}$ Rachel Marie B. Rosario ${ }^{2}$ and Romeo V. Marcaida ${ }^{2}$ \\ ${ }^{1}$ Section of Medical Oncology, Department of Medicine, College of Medicine and Philippine General Hospital, University of the Philippines Manila \\ ${ }^{2}$ Philippine Cancer Society Inc., Manila, Philippines \\ ${ }^{3}$ Department of Health-National Center for Pharmaceutical Access and Management, Philippines
}

\begin{abstract}
Introduction. Cost has become a limiting factor for indigent breast cancer patients at the Philippine General Hospital (PGH). The Department of Health-Philippine Cancer Society Inc (DOHPCSI) Access Program for Breast Cancer Medicine provided free chemotherapy through a patient navigation system in $\mathrm{PGH}$ starting January 2012 to improve breast cancer treatment quality. This study looked into the differences of quality care in the non-metastatic setting among enrolled patients in the first 6 months compared to patients outside of the program from 2011-2012.
\end{abstract}

Methods. This retrospective cohort used follow-up rates and 19 quality care indicators linked to improved outcomes to look into quality of care among patients who were enrolled $(n=58)$ and those who were not ( $n=118$ for 2011 and 2012). Subgroup analyses compared patients in the program and those who were not included in the same period $(n=28)$. Another analysis compared 2011 patients $(n=90)$ with those in $2012(n=86)$. Ztest for the difference of proportions was done.

Results. Attrition rate decreased from $62 \%$ in 2011 to $18 \%$ in $2012(p<.0001)$.There was a significant improvement in 12 quality care indicators in the program $(95 \% \mathrm{Cl})$, with the greatest differences in the initiation of treatment (58.7\%) and appropriate neo-adjuvant chemotherapy administration (58.3\%). Similar trends were seen in the subgroup analyses.

Conclusion. The DOH-PCSI Access Program for Breast Cancer Medicine program improved care among breast cancer patients in PGH, noted as early as within its first six months.

Key Words: access for breast cancer medicine, patient navigation, quality care

\footnotetext{
Presented and won 1st Place at the Philippine Society of Medical Oncology Annual Convention Research Forum, October 2012, Manila; presented at the Asian Oncology Summit, 2013, Bangkok, with abstract published in European J Cancer 03/2013; 49, Supplement 1:S9.

Corresponding author: Corazon A. Ngelangel, MD, MS, PhD

Section of Medical Oncology

Department of Medicine

Philippine General Hospital

University of the Philippines Manila

Taft Avenue, Ermita, Manila 1000 Philippines

Tele/Fax: +632 5263775

Email: corazon.ngelangel@gmail.com
}

Introduction

Breast cancer is one of the leading causes of cancer death in the Philippines. ${ }^{1}$ To decrease these rates of mortality, screening programs and adjuvant chemotherapy are interventions that could be implemented as exemplified in many developed countries. ${ }^{2}$ Inadequate resources and inadequate teams have been cited as barriers to these measures of cancer care. ${ }^{3}$ One published local study similarly identified cultural and logistic barriers as reasons why patients are not able to pursue even the diagnostic follow-up. ${ }^{4}$

In May 2011, the Department of Health (DOH) in collaboration with Philippine Cancer Society, Inc. (PCSI) has started the Breast Cancer Medicines Access Program through a patient navigation scheme with the goal of promoting early screening and cancer awareness and improving survival rates of breast cancer among Filipinos. Four government hospitals were chosen to participate because of the presence of support and multidisciplinary breast cancer care.5,6 The Philippine General Hospital (PGH) which serves indigent patients in its Cancer Institute started recruiting patients in this program in January 2012.

The program utilizes patient navigation in its implementation. The concept of patient navigation, which started in the United States in the nineties, is increasing in use in the last decade with the aim of improving access to cancer care among disadvantaged patients. ${ }^{7}$ The PCSI Patient Navigation Program in this scheme is relegated to monitoring of these patients in terms of treatment response, occurrence of adverse drug experiences, research, coordination with health providers, assistance to patients to overcome healthcare barriers and psychosocial support. In each of the sites, the program provides nurses as patient navigators who function in the coordination and support of patients. ${ }^{6}$

The program aims to address one of the barriers in cancer care by providing free chemotherapy for patients with early breast cancer (Stage I-IIIA). In June 2012, it expanded to include IIIB and IIIC patients. Testing for estrogen receptor/progesterone receptor $(\mathrm{ER} / \mathrm{PgR})$ and 
Her2Neu immune-histochemical (IHC) staining are also free for these patients. For those recommended to have hormonal treatment, tamoxifen is provided.

The effects of this program in the long term are best adjudged by its effect on survival outcomes. The program, however, is still in its infancy and the use of follow-up rates and quality indicators are proposed as surrogate markers to aid its initial evaluation. Several methods aiming at validation of quality of care indicators arrived at by literature review and multidisciplinary consensus have been done. ${ }^{8-10}$ Cheng, et al ${ }^{10}$ first linked $100 \%$ adherence to quality indicators to improvement in overall survival and disease free survival.

This study assesses the effect of the implementation of the DOH-PCSI medicine access program for non-metastatic breast cancer on quality of care using evidence-based quality indicators and follow-up rates. The study also aims to identify what areas of cancer care lag in improvement in this program and propose areas of further study and action.

\section{Methods}

\section{Study design}

This retrospective cohort study reviewed the charts of all non-metastatic breast cancer patients whose first consult in our institution falls from 2011 to June 2012. Quality of care was assessed by previously studied quality indicators for breast cancer deemed appropriate in the local setting and the objectives of the DOH-PCSI program.

The study was done in the Philippine General Hospital Cancer Institute, a tertiary referral center. It is one of 4 hospitals where the DOH-PCSI program is implemented. The study was limited to the Medical Oncology Clinic, one of two charity service clinics in the hospital that handles chemotherapy of breast cancer patients. The protocol was approved by the Technical Research Board of the Department of Medicine and the Expanded Hospital Research Office of the Philippine General Hospital.

\section{Study Participants}

This study identified all patients diagnosed with Stage I-III Breast Cancer whose first consult in the charity service Medical Oncology clinic was from 2011 to June 30, 2012. Patients with metastatic breast cancer or recurrent breast cancer at the time of consult or on initial work-up were excluded.

\section{Data Collection}

Patients' baseline characteristics were collected from the patients' medical chart. The fulfillment of each of the 19 quality indicators and the status of follow-up was assessed by the investigators from the chart review. Reasons for exclusion in the program were noted.

Quality indicators (Table 1) based on Del Turco et al's study $^{8}$ and Cheng et $\mathrm{al}^{10}$ were chosen by consensus of the authors based on its relevance to the Department of HealthPhilippine Cancer Society guidelines.

Table I. Quality care indicators

\begin{tabular}{|c|c|c|c|}
\hline & Title & Definition & Level \\
\hline & $\begin{array}{l}\text { Completeness } \\
\text { of prognostic or } \\
\text { predictive } \\
\text { characterization }\end{array}$ & $\begin{array}{l}\text { The proportion of invasive cancer cases } \\
\text { with primary surgery, for which the } \\
\text { following prognostic/predictive } \\
\text { parameters have been recorded: }\end{array}$ & II \\
\hline 1 & & - Histological type & \\
\hline 2 & & - Grading & \\
\hline 3 & & - ER \&PgR & \\
\hline 4 & & - HER 2 & \\
\hline 5 & & - Pathological stage (T and N) & \\
\hline 6 & & - Size in $\mathrm{mm}$ for the invasive component & \\
\hline 7 & & - Peritumoral vascular invasion & \\
\hline 8 & & - Distance to nearest radial margin & \\
\hline 9 & Waiting time & $\begin{array}{l}\text { Time between the date of first diagnostic } \\
\text { examination within the breast unit and the } \\
\text { date of surgery or start of other treatment } \\
\text { within } 6 \text { weeks }\end{array}$ & IV \\
\hline 10 & $\begin{array}{l}\text { Post-operative } \\
\text { RT }\end{array}$ & $\begin{array}{l}\text { The proportion of patients with invasive } \\
\text { breast cancer (M0) who received post- } \\
\text { operative radiotherapy after surgical } \\
\text { resection of the primary tumour and } \\
\text { appropriate axillary staging/surgery in the } \\
\text { framework of BCT. }\end{array}$ & I \\
\hline 11 & $\begin{array}{l}\text { Post-operative } \\
\text { RT }\end{array}$ & $\begin{array}{l}\text { The proportion of patients with } \\
\text { involvement of axillary lymph nodes (P } \\
\text { pN2a) who received post-mastectomy } \\
\text { radiotherapy. }\end{array}$ & I \\
\hline 12 & $\begin{array}{l}\text { Appropriate } \\
\text { hormone } \\
\text { therapy }\end{array}$ & $\begin{array}{l}\text { The proportion of patients with endocrine } \\
\text { sensitive invasive carcinoma who received } \\
\text { hormone therapy, out of the total number } \\
\text { of patients with this diagnosis. }\end{array}$ & I \\
\hline 13 & $\begin{array}{l}\text { Appropriate } \\
\text { chemotherapy }\end{array}$ & $\begin{array}{l}\text { The proportion of patients with ER- }(\mathrm{T}>1 \\
\mathrm{cm} \text { or Node }+) \text { invasive carcinoma who } \\
\text { received adjuvant chemotherapy, out of } \\
\text { the total number of patients with the same } \\
\text { diagnosis. }\end{array}$ & I \\
\hline 14 & $\begin{array}{l}\text { Appropriate } \\
\text { chemotherapy }\end{array}$ & $\begin{array}{l}\text { The proportion of patients with } \\
\text { inflammatory breast cancer (IBC) or locally } \\
\text { advanced non-resectable ER carcinoma } \\
\text { who had neo-adjuvant chemotherapy over } \\
\text { the total of patients with the same } \\
\text { diagnosis. }\end{array}$ & II \\
\hline 15 & $\begin{array}{l}\text { Appropriate } \\
\text { staging } \\
\text { procedure }\end{array}$ & $\begin{array}{l}\text { The proportion of women with stage I } \\
\text { breast cancer who do not undergo baseline } \\
\text { staging tests (US of liver, chest X-ray and } \\
\text { bone scan). }\end{array}$ & III \\
\hline 16 & $\begin{array}{l}\text { Appropriate } \\
\text { staging } \\
\text { procedure }\end{array}$ & $\begin{array}{l}\text { The proportion of women with stage III } \\
\text { breast cancer who undergo baseline } \\
\text { staging tests (US of liver, chest X-ray and } \\
\text { bone scan). }\end{array}$ & III \\
\hline 17 & $\begin{array}{l}\text { Perform } \\
\text { appropriate } \\
\text { follow-up }\end{array}$ & $\begin{array}{l}\text { The proportion of asymptomatic patients } \\
\text { who undergo routine annual } \\
\text { mammographic screening and clinical } \\
\text { evaluation every } 6 \text { months in the first } 5 \\
\text { years after the operation. }\end{array}$ & I \\
\hline 18 & $\begin{array}{l}\text { Avoid } \\
\text { inappropriately } \\
\text { intensive } \\
\text { follow-up }\end{array}$ & $\begin{array}{l}\text { The proportion of asymptomatic patients } \\
\text { who do not undergo a follow-up protocol } \\
\text { more intensive than local examination } \\
\text { (mammography, US and clinical } \\
\text { evaluation every } 6 / 12 \text { months in the first } 5 \\
\text { years after the operation). }\end{array}$ & I \\
\hline 19 & $\begin{array}{l}\text { Appropriate } \\
\text { chemotherapy }\end{array}$ & $\begin{array}{l}\text { Any patient regardless of age who started } \\
\text { adjuvant chemotherapy should complete } \\
\text { at least } 4 \text { cycles }\end{array}$ & II \\
\hline
\end{tabular}


Recommendations on trastuzumab were not included in the analysis as only 4 patients received it and this was after June 2012 in the context of a clinical trial.

The quality indicator for multidisciplinary discussions was also not included because of the difference in the context of application in our setting. Presently, the setting that multidisciplinary consult happens in the institution is via referral of the patient from Surgery, Medical Oncology, Radiation Oncology, and other clinics in the Cancer Institute.

Lost to follow up (attrition) was defined as no follow-up for more than 90 days since last scheduled follow-up in the clinic.

\section{Data analysis}

The proportions of patients who fulfilled each quality indicator were taken. The difference in proportions and Ztest for the difference of proportions for every quality indicator comparing patients enrolled in the program and those who were not (2011-2012 patients) were done using Microsoft Excel and Stata 10.0, respectively. A p-value of $<0.05$ was considered significant. The same method was used to carry out analysis for the following subgroups: all patients seen in 2011 compared with all patients seen in 2012; and all patients enrolled in the program versus those who were excluded in 2012.

\section{Ethical considerations}

All data taken from the patients' records were kept private and confidential. Consent for participation in the access program including use of data was taken from each patient.

\section{Limitations of the study}

Data on specific reasons for attrition and noncompliance were not gathered. Also, the reasons particular quality indicators were not done were not recorded because the retrospective nature of the study may limit available data. Thus, data on whether it is due to patient or physician factors are not captured. Outcomes of adherence to these quality indicators, such as disease-free survival and overall survival, were not included since data are still immature given that the DOH-PCSI program has been running for only 7 months at the time of writing.

\section{Results}

Among the 264 new breast cancer patients seen from 2011 to June 2012 listed in the Medical Oncology Outpatient logbook, 88 metastatic or recurrent breast cancer patients were excluded in this study. Of the 176 patients included, 90 were seen in 2011 and 86 were seen in the first half of 2012. The average number of non-metastatic breast cancer patients seen per month has increased by 91\% from 2011 to 2012.

Fifty eight of the 86 patients seen in 2012 were enrolled in the DOH-PCSI program. This is 39.7\% (58/146) of enrolled patients in the first half of the year while the rest were being seen in the Breast Care Clinic under the Department of Surgery. Twenty eight patients were not enrolled in the program from January to June 2012 (Table 2).

Table 2. Reasons for patients not being included in the DOH-PCSI

\begin{tabular}{lc}
\hline Reason for not being included in the DOH PCSI & No. of Patients $(\mathbf{n}=\mathbf{2 8})$ \\
\hline Lost to follow-up & 10 \\
Stage IIIB or IIIC & 8 \\
Prior chemotherapy in other institutions & 6 \\
Awaiting disposition/surgery as of July 31, 2012 & 3 \\
First consult beyond 12 weeks post-surgery & 1 \\
\hline
\end{tabular}

\section{Patient characteristics}

The average age of patients was 48 years (range $=25-77$ ). The most common histopathology reported was invasive ductal carcinoma. There was no noted difference in the stages of breast cancer in 2011 and 2012 (Table 3). Majority (74.4\%) of non-metastatic breast cancer patients seen in the Medical Oncology Clinic had biopsy and/or surgery done outside of the hospital. Among those who had surgery, there was a $2.8 \%(3 / 107)$ breast-conserving therapy (BCT) rate among those from outside and $7.1 \%$ (3/41) BCT rate among those who had surgery in the Philippine General Hospital.

The patients seen in 2012 who were not included in the DOH program were compared with the 2011 data. None of the 19 quality indicators had shown a significant difference between the two groups.

Comparison between patients enrolled in the program and all patients from 2011-2012 who were not included showed a significant increase in 12 out of 18 quality care indicators (Table 4). The greatest improvements were seen in the time from date of consult to initiation of treatment (58.7\%), neoadjuvant chemotherapy for locally advanced non-resectable breast cancer $(58.3 \%)$, and post-operative RT for pathologic N2 disease $(51.5 \%)$. The smallest improvements were seen in the quality indicators on pathologic reporting of histologic type, size in millimeters of invasive component, and distance to the radial margin. While Her2Neu testing (93\%) is still less than ER/PgR immune-histochemical (IHC) staining (98.2\%) under the $\mathrm{DOH}$ program, there was a bigger increase in the rates of the former compared to patients outside the program. There was also a decrease in 3/18 quality indicators but only pathologic reporting of peritumoral invasion had statistical significance. Peritumoral invasion is sometimes not reported on the surgical pathological report; the presence of such 'project' might have prompted more complete reporting. Appropriate and adequate neoadjuvant chemotherapy among DOH Breast Cancer Patients perhaps decreased the peritumoral invasion in these patients. 
Table 3. Patient characteristics

\begin{tabular}{|c|c|c|c|c|c|c|}
\hline & $\begin{array}{c}\text { Patients enrolled } \\
\text { in the program } \\
n=58\end{array}$ & $\begin{array}{c}\text { Patients not } \\
\text { enrolled (2012) } \\
n=28\end{array}$ & $\begin{array}{l}\text { Patients enrolled vs } \\
\text { patients not enrolled in } \\
2012 \text { ( p value) }\end{array}$ & $\begin{array}{c}\text { Patients seen } \\
\text { in } 2012 \\
n=86\end{array}$ & $\begin{array}{c}\text { Patients seen in } \\
\begin{array}{c}2011 \\
n=90\end{array}\end{array}$ & $\begin{array}{l}\text { Patients seen in } 2012 \text { vs } \\
\text { patients seen in } 2011 \\
\text { (p value) }\end{array}$ \\
\hline Age (Range, years) & $27-65$ & $25-66$ & & $25-66$ & $28-77$ & \\
\hline Postmenopausal & 32 & 19 & 0.262 & 51 & 56 & 0.69 \\
\hline \multicolumn{7}{|l|}{ Histology } \\
\hline Invasive Ductal & 56 & 23 & 0.020 & 79 & 81 & 0.668 \\
\hline Invasive Lobular & 0 & 1 & 0.147 & 1 & 4 & 0.190 \\
\hline Mucinous & 0 & 2 & 0.039 & 2 & 1 & 0.534 \\
\hline Medullary & 2 & 0 & 0.320 & 2 & 0 & 0.146 \\
\hline Papillary & 0 & 1 & 0.147 & 1 & 3 & 0.334 \\
\hline \multicolumn{7}{|l|}{ Stage (AJCC) } \\
\hline$I^{0}$ & $1(0.02)$ & $2(0.07)$ & 0.199 & $3(0.03)$ & $3(0.03)$ & 0.955 \\
\hline II & $35(0.61)$ & $7(0.25)$ & 0.002 & $42(0.49)$ & $40(0.44)$ & 0.559 \\
\hline III & $21(0.37)$ & 19(0.67) & 0.006 & $40(0.47)$ & $47(0.52)$ & 0.449 \\
\hline $\begin{array}{l}\text { Histopathology reports from } \\
\text { PGH }\end{array}$ & $13(0.22)$ & $5(0.17)$ & 0.626 & $18(0.21)$ & $27(0.3)$ & 0.168 \\
\hline Lost to follow-up & $0 / 34(0)$ & $10 / 21(0.48)$ & 0.00 & $10 / 55(0.18)$ & $56 / 90(0.62)$ & 0.00 \\
\hline $\begin{array}{l}\text { Lost to ff-up w/o starting } \\
\text { chemo if warranted }\end{array}$ & -- & $7 / 9$ & -- & $7 / 9$ & $26 / 56$ & 0.081 \\
\hline $\begin{array}{l}\text { Lost to ff up without finishing } \\
\text { at least } 4 \text { chemo }\end{array}$ & -- & $0 / 9$ & -- & $0 / 9$ & $17 / 56$ & 0.054 \\
\hline MRM specimens & 50 & 17 & 0.008 & 67 & 82 & 0.015 \\
\hline BCT & 0 & 1 & 0.148 & 1 & 5 & 0.108 \\
\hline
\end{tabular}

Table 4. Comparison of quality care indicators between patients enrolled in the DOH-PCSI program and all patients not enrolled from 2011-2012

\begin{tabular}{|c|c|c|c|c|}
\hline & $\begin{array}{l}\text { Patients enrolled in } \\
\text { the DOH-PCSI } \\
\text { program }\end{array}$ & $\begin{array}{l}\text { Patients not enrolled in } \\
\text { the DOH-PCSI } \\
\text { program }\end{array}$ & Difference & $\mathrm{p}$ value \\
\hline Histological type & $58 / 58(1.000)$ & $115 / 118(0.975)$ & 0.025 & 0.112 \\
\hline Grading (according to EU Guidelines) & $44 / 58(0.759)$ & $64 / 113(0.566)$ & 0.193 & 0.007 \\
\hline ER \&PgR & $56 / 57(0.982)$ & $75 / 109(0.688)$ & 0.294 & 0.000 \\
\hline HER2 & $53 / 57(0.930)$ & $62 / 109(0.574)$ & 0.356 & 0.000 \\
\hline Pathological stage ( $\mathrm{T}$ and $\mathrm{N}$ ) & $9 / 50(0.180)$ & $27 / 99(0.273)$ & -0.093 & 0.106 \\
\hline Size in $\mathrm{mm}$ for the invasive component & $52 / 53(0.981)$ & $88 / 101(0.871)$ & 0.110 & 0.012 \\
\hline Peritumoral vascular invasion & $23 / 54(0.426)$ & 69/99(0.697) & -0.271 & 0.001 \\
\hline Distance to nearest radial margin & $39 / 51(0.765)$ & $70 / 98(0.714)$ & 0.051 & 0.255 \\
\hline $\begin{array}{l}\text { Time between the date of consult within the breast unit and the date of surgery } \\
\text { or start of other treatment within } 6 \text { weeks }\end{array}$ & $53 / 58(0.914)$ & $37 / 113(0.327)$ & 0.587 & 0.000 \\
\hline Post-operative RT after BCT & -- & $4 / 6(0.667)$ & -- & --- \\
\hline Post-operative RT for pN2 & $5 / 5(1.000)$ & $16 / 33(0.485)$ & 0.515 & 0.016 \\
\hline $\begin{array}{l}\text { Appropriate hormone therapy } \\
\text { endocrine sensitive invasive carcinoma who received hormone therapy }\end{array}$ & $6 / 6(1.000)$ & $21 / 40(0.525)$ & 0.475 & 0.014 \\
\hline $\begin{array}{l}\text { Appropriate chemotherapy } \\
\text { ER- }(\mathrm{T}>1 \mathrm{~cm} \text { or Node+) invasive carcinoma who received adjuvant } \\
\text { chemotherapy }\end{array}$ & $22 / 23(0.957)$ & $27 / 44(0.600)$ & 0.357 & 0.001 \\
\hline $\begin{array}{l}\text { Appropriate chemotherapy } \\
\text { (IBC) or locally advanced non-resectable carcinoma who had neo-adjuvant } \\
\text { chemotherapy }\end{array}$ & $6 / 6(1.000)$ & $15 / 36(0.417)$ & 0.583 & 0.004 \\
\hline $\begin{array}{l}\text { Appropriate staging procedure } \\
\text { stage I breast cancer who do not undergo baseline staging }\end{array}$ & $0 / 1(0)$ & $2 / 5(0.4)$ & -0.4 & 0.194 \\
\hline $\begin{array}{l}\text { Appropriate staging procedure } \\
\text { stage III breast cancer who undergo baseline staging tests }\end{array}$ & $13 / 21(0.619)$ & $24 / 66(0.367)$ & 0.252 & 0.020 \\
\hline Perform appropriate follow-up & $7 / 9(0.778)$ & $26 / 61(0.426)$ & 0.352 & 0.024 \\
\hline Avoid inappropriately intensive follow-up & $10 / 11(0.909)$ & $51 / 61(0.830)$ & 0.079 & 0.268 \\
\hline At least 4 chemo once started & $34 / 35(0.971)$ & $46 / 74(0.622)$ & 0.349 & 0.000 \\
\hline
\end{tabular}


Pre-planned subgroup analysis comparing patients enrolled in the program and those not enrolled in 2012 revealed a significant increase in 9 out of 18 quality care parameters, with the most significant improvements at $72.7 \%$ for appropriate chemotherapy for ER(-) patients and $65.5 \%$ in the time between the date of consult and initiation of treatment (Table 5). There was also a significant increase in the reporting of grade, hormonal status, and Her2neu status. Administration of hormone therapy, chemotherapy, performance of appropriate baseline staging tests for stage III also improved. Reporting of histologic type and followup also increased but did not reach statistical significance.
Subgroup analysis comparing all patients in 2011 and all patients in 2012 showed statistically significant increase in 8 out of 19 indicators, with the biggest difference in radiation therapy for pathologic $\mathrm{N} 2(58.5 \%)$, post-operative RT after BCT (40.0\%), time between the date of consult and initiation of treatment $(35.7 \%)$ and completion of at least 4 chemotherapy cycles once started $(31.0 \%)$ favoring patients managed in 2012 (Table 6). Reporting of histologic type, grade, and distance to nearest radial margin, performance of neoadjuvant chemotherapy, appropriate hormone therapy and follow-up also increased but did not reach statistical significance.

Table 5. Comparison of quality care indicators between patients enrolled in the DOH-PCSI program and patients not enrolled in the program in 2012

\begin{tabular}{|c|c|c|c|c|}
\hline Quality Indicator & $\begin{array}{l}\text { Patients enrolled } \\
\text { in the DOH-PCSI } \\
\text { program }\end{array}$ & $\begin{array}{l}\text { Patients not enrolled in the } \\
\text { DOH-PCSI program } \\
(2012)\end{array}$ & Difference & $P$ value \\
\hline Histological type & $58 / 58(1.000)$ & $27 / 28(0.964)$ & 0.036 & 0.073 \\
\hline Grading (according to EU Guidelines) & $44 / 58(0.759)$ & $13 / 26(0.500)$ & 0.259 & 0.010 \\
\hline ER \&PgR & $56 / 57(0.982)$ & $15 / 21(0.714)$ & 0.268 & 0.000 \\
\hline HER 2 & $53 / 57(0.930)$ & $13 / 21(0.619)$ & 0.311 & 0.000 \\
\hline Pathological stage ( $\mathrm{T}$ and $\mathrm{N}$ ) & $9 / 50(0.180)$ & $5 / 17(0.294)$ & -0.114 & 0.159 \\
\hline Size in $\mathrm{mm}$ for the invasive component & $52 / 53(0.981)$ & $18 / 18(1.000)$ & -0.019 & 0.278 \\
\hline Peritumoral vascular invasion & $23 / 54(0.426)$ & $14 / 18(0.778)$ & -0.352 & 0.005 \\
\hline Distance to nearest radial margin & $39 / 51(0.765)$ & $15 / 17(0.882)$ & -0.117 & 0.149 \\
\hline $\begin{array}{l}\text { Time between the date of consult within the breast unit and the date of surgery } \\
\text { or start of other treatment within } 6 \text { weeks }\end{array}$ & $53 / 58(0.914)$ & $7 / 27(0.259)$ & 0.655 & 0.000 \\
\hline Post-operative RT after BCT & -- & $1 / 1(1.000)$ & -- & --- \\
\hline Post-operative RT for $\mathrm{pN} 2$ & $5 / 5(1.000)$ & $4 / 4(1.000)$ & 0.000 & \\
\hline $\begin{array}{l}\text { Appropriate hormone therapy } \\
\text { endocrine sensitive invasive carcinoma who received hormone therapy }\end{array}$ & $6 / 6(1.000)$ & $2 / 4(0.500)$ & 0.500 & 0.026 \\
\hline $\begin{array}{l}\text { Appropriate chemotherapy } \\
\text { ER- }(\mathrm{T}>1 \mathrm{~cm} \text { or } \mathrm{Node}+) \text { invasive carcinoma who received adjuvant } \\
\text { chemotherapy }\end{array}$ & $22 / 23(0.957)$ & $3 / 5(0.600)$ & 0.357 & 0.010 \\
\hline $\begin{array}{l}\text { Appropriate chemotherapy } \\
\text { (IBC) or locally advanced non-resectable carcinoma who had neo-adjuvant } \\
\text { chemotherapy }\end{array}$ & $6 / 6(1.000)$ & $3 / 11(0.273)$ & 0.727 & 0.002 \\
\hline $\begin{array}{l}\text { Appropriate staging procedure } \\
\text { stage I breast cancer who do not undergo baseline staging }\end{array}$ & $0 / 1(0)$ & $1 / 2(0.500)$ & -0.500 & 0.173 \\
\hline $\begin{array}{l}\text { Appropriate staging procedure } \\
\text { stage III breast cancer who undergo baseline staging tests }\end{array}$ & $13 / 21(0.619)$ & $3 / 19(0.158)$ & 0.461 & 0.002 \\
\hline Perform appropriate follow-up & $7 / 9(0.778)$ & $2 / 5(0.400)$ & 0.378 & 0.079 \\
\hline Avoid inappropriately intensive follow-up & $10 / 11(0.909)$ & $3 / 5(0.600)$ & 0.309 & 0.071 \\
\hline At least 4 chemo once started & $34 / 35(0.971)$ & $8 / 11(0.727)$ & 0.244 & 0.006 \\
\hline
\end{tabular}


Table 6. Comparison of quality care indicators between patients seen in 2012 and patients seen in 2011

\begin{tabular}{|c|c|c|c|c|}
\hline Quality Indicator & Patients seen in 2012 & Patients seen in 2011 & Difference & P value \\
\hline Histological type & $85 / 86(0.988)$ & $88 / 90(0.978)$ & 0.010 & 0.294 \\
\hline Grading (according to EU Guidelines) & $57 / 84(0.679)$ & $51 / 87(0.586)$ & 0.093 & 0.105 \\
\hline ER \&PgR & $71 / 78(0.910)$ & $60 / 88(0.682)$ & 0.228 & 0.000 \\
\hline HER 2 & $66 / 78(0.846)$ & $49 / 88(0.557)$ & 0.289 & 0.000 \\
\hline Pathological stage (T and N) & $14 / 67(0.209)$ & $22 / 82(0.268)$ & -0.059 & 0.200 \\
\hline Size in $\mathrm{mm}$ for the invasive component & $70 / 71(0.986)$ & $70 / 83(0.843)$ & 0.143 & 0.001 \\
\hline Peritumoral vascular invasion & $37 / 72(0.514)$ & $55 / 81(0.679)$ & -0.165 & 0.019 \\
\hline Distance to nearest radial margin & $54 / 68(0.794)$ & $55 / 81(0.679)$ & 0.115 & 0.057 \\
\hline $\begin{array}{l}\text { Time between the date of consult within the breast unit and the date of surgery } \\
\text { or start of other treatment within } 6 \text { weeks }\end{array}$ & $60 / 85(0.706)$ & $30 / 87(0.345)$ & 0.357 & 0.000 \\
\hline Post-operative RT after BCT & $1 / 1(1.000)$ & $17 / 41(0.600)$ & 0.400 & 0.033 \\
\hline Post-operative RT for pN2 & $9 / 9(1.000)$ & $13 / 29(0.448)$ & 0.585 & 0.002 \\
\hline $\begin{array}{l}\text { Appropriate hormone therapy } \\
\text { endocrine sensitive invasive carcinoma who received hormone therapy }\end{array}$ & $8 / 10(0.800)$ & $19 / 36(0.528)$ & 0.272 & 0.061 \\
\hline $\begin{array}{l}\text { Appropriate chemotherapy } \\
\text { ER- }(T>1 \mathrm{~cm} \text { or Node }+) \text { invasive carcinoma who received adjuvant } \\
\text { chemotherapy }\end{array}$ & $25 / 28(0.893)$ & $12 / 25(0.615)$ & 0.278 & 0.001 \\
\hline $\begin{array}{l}\text { Appropriate chemotherapy } \\
\text { (IBC) or locally advanced non-resectable carcinoma who had neo-adjuvant } \\
\text { chemotherapy }\end{array}$ & $9 / 17(0.529)$ & $12 / 25(0.480)$ & 0.049 & 0.376 \\
\hline $\begin{array}{l}\text { Appropriate staging procedure } \\
\text { stage I breast cancer who do not undergo baseline staging }\end{array}$ & $1 / 3(0.330)$ & $1 / 3(0.33)$ & 0 & 0.500 \\
\hline $\begin{array}{l}\text { Appropriate staging procedure } \\
\text { stage III breast cancer who undergo baseline staging tests }\end{array}$ & $16 / 40(0.40)$ & $21 / 47(0.44)$ & -0.04 & 0.330 \\
\hline Perform appropriate follow-up & $9 / 14(0.643)$ & $24 / 56(0.429)$ & 0.214 & 0.075 \\
\hline Avoid inappropriately intensive follow-up & $13 / 16(0.813)$ & $48 / 56(0.857)$ & -0.044 & 0.331 \\
\hline At least 4 chemo once started & $42 / 46(0.913)$ & $38 / 63(0.603)$ & 0.310 & 0.000 \\
\hline
\end{tabular}

\section{Discussion}

The increase in the numbers of nonmetastatic breast cancer patients seeking consult in our clinic by $91 \%$ in 2012 shows an increase in the coverage of care. The significance of this increase is compounded by a large attrition rate $(62 \%)$ in 2011 compared to $18 \%$ in 2012. This finding greatly affects the interpretation of the baseline quality of care as indicators like immune-histochemical staining for ER/PgR, Her2Neu, appropriate staging procedure for stage I or III would mostly be recorded as not done where they would have been applicable. For instance, 32\% of patients in 2011 did not have $\mathrm{ER} / \mathrm{PgR}$ testing even if immune-histochemical staining is available in the hospital and blocks of the specimen can be requested for processing if surgery was done in another institution. The proportion of patients who didn't have Her2neu testing (44.3\%) also seems high. These percentages seem high for a tertiary institution but on further analysis more than half of these are patients that have been lost to follow-up. Hence, data in this study should always be interpreted in light of these poor lost to follow-up rates not seen in similar studies. ${ }^{11,12}$

A peculiar characteristic of the attrition rates from 2011 to 2012 is that patients are lost even before finishing at least 4 cycles of chemotherapy $(25.8 \%)$ or even prior to starting chemotherapy (39\%). All of those lost to follow-up have not been initially enrolled in the $\mathrm{DOH}$ program so this may suggest that access to free chemotherapy is a significant factor spelling the difference in the follow-up rates between inclusion and exclusion in the program. Patient navigation may also contribute to this difference. The extent each of these reasons contributes may be explored in future studies.

Since part of the program's objectives is the encouragement of early screening, ${ }^{6}$ it would be the goal of the program to skew the distribution to more Stage I and II patients relative to Stage III. This was not anticipated yet in the first six months of implementation as this data showed. A greater proportion of patients are found to be in the Stage III compared to Stage I and II breast cancer when compared to published data on breast cancer epidemiology in Metro Manila and Rizal Province from 1993-2002.13 Subsequent analyses as the program matures will have to take note of the trends in this stage distribution to assess whether we are indeed promoting early screening.

\section{Comparison of 2012 Data}

Similar trends were seen between the comparison of DOH-PCSI patients with all those outside the program from 2011-June 2012 and the comparison of those included and not included within 2012 alone. Remarkably, improvements in quality indicators with free services favor the patients in the program consistently in both the magnitude and statistical significance of the difference. These include chemotherapy, hormone therapy, and ER/PgR/Her2neu testing.

The difference between appropriate staging procedure have increased as well in the within 2012 comparison but has not sustained statistical significance because of the small sample size. While finances may play a part in this increased 
trend, as the patients are already free from the costs of chemotherapy and may use these instead for the diagnostics, these data can only be suggested in this study. There is no difference in rates of RT for pathologic N2 disease within 2012 unlike in the main comparison. Although the small sample size limits this analysis, it could be hypothesized that improvements may be confounded by other factors such as the availability of radiotherapy in the institution, hence, the more pronounced difference in the comparison between two time periods (2011 vs 2012) regardless of inclusion in the program.

As a preliminary study, it was expected that 2012 data on surveillance, which includes appropriate follow-up and avoidance of inappropriately intensive follow-up, and radiation therapy are still immature because most of patients are still ongoing chemotherapy so there were smaller sample sizes and statistically insignificant results. This remains a crucial area to follow-up in the program.

\section{Comparison of 2011 and 2012 Data}

The comparison between the quality indicators between 2011 and the first half of 2012 was done to reflect the impact of exclusion of certain patients in the overall performance of the clinic. Less quality indicators have improved in 2012 when patients excluded in 2012 significantly contribute to a poorer overall performance. For instance, rate of neoadjuvant chemotherapy for locally advanced breast cancer was marginally increased and was not statistically significant in this comparison. The effect of $100 \%$ adherence of those in the program to this indicator was diluted due to the poor rates in those who were not included in the program. This was anticipated since stage IIIB and IIIC patients in 2012 were excluded earlier on in the program to prioritize the resources to those with better prognosis.

Identified reasons for exclusion are proposed to be targeted for improvement of the program particularly in optimizing enrolment of eligible patients.

Patients lost to follow-up earlier on contribute a lot to exclusion and an understanding of possible cultural and logistic problems may provide inputs into the management and evaluation of the patient navigation scheme which is intended to address these barriers.

Another source of exclusion in the program is having patients start chemotherapy outside of the institution then referred to PGH. This has more complex considerations but this often happens in a setting where the patients are unable to sustain the costs of initial chemotherapy. Another reason for exclusion is the delay in consult for chemotherapy after surgery. These may warrant investigation whether physicians' awareness of the existence of the program and physicians' assessment of patients who will most benefit from the support of the program earlier on is significant to increasing inclusion in the program.
Exclusion because of locally advanced breast cancer has recently been targeted by increasing coverage to include them in the program. The impact of this on cost-effectiveness remains to be determined and does not preclude this as a problem primarily of earlier screening.

\section{Other trends of comparisons}

In the 3 main comparisons, the elements of pathology reporting have the most inconsistent results showing improvements and deterioration in some factors, small magnitude of differences with statistical significance or statistically insignificant results across the 3 main comparisons. Given that most of the patients already have pathology reports when they first consult the Philippine General Hospital, the investigators anticipated little differences if any among these indicators with the institution of the program. This highlights a possible area of improvement for the program. While we achieve higher rates of access to medicines, the choice of subsequent treatment is better guided with better characterization and individualization of treatment to these patients. This can be achieved by setting standards in coordination with the pathologists even from other institutions as to the reporting of these specimens.

Appropriate follow-up, radiation therapy and appropriate staging are also areas which show the least effects impact or the least consistent results among these comparisons. Distilling the reasons, whether these are patient factors or physician factors can further identify areas of improvement in quality of care. Among these, however, access to radiation therapy is anticipated to be most prohibitive because of the costs.

Based on this study, we recommend a multidisciplinary effort in defining quality indicators applicable to the local setting and validation of its link to hard endpoints such as overall survival and disease free survival in the local setting. Building multidisciplinary teams with regular meetings at its core as it is increasingly recognized to improve outcomes in cancer care is an area of improvement in our institution.

Further studies to include patients under the Breast Care Clinic will give us a better picture of baseline characteristics important in analyzing quality care such as follow-up rates, distribution of cancer stage on consult, and institutional BCT rates.

\section{Conclusion}

The DOH-PCSI Breast Cancer Medicines Access Program improved the quality of care among patients with breast cancer at the Medical Oncology Clinic-PGH in 12 of 18 quality indicators and follow-up rates within the first six months of its implementation. Characterization of cancer by pathology reporting, appropriate follow-up and appropriate staging seemed to be areas that lag in this improvement. 


\section{References}

1. Laudico A, Medina V, Lumague M, et al. 2010 Philippine Cancer Facts and Estimates. Manila: Philippine Cancer Society Inc, 2010.

2. Youlden DR, Cramb SM, Dunn NA, et al. The descriptive epidemiology of female breast cancer: an international comparison of screening, incidence, survival and mortality. Cancer Epidemiol. 2012; 36(3):23748 .

3. Walsh J, Harrison JD, Young JM, Butow PN, Solomon MJ, Masya L. What are the current barriers to effective cancer care coordination? A qualitative study.BMC Health Serv Res. 2010; 10:132.

4. Pisani P, Parkin DM, Ngelangel C, et al. Outcome of screening by clinical examination of the breast in a trial in the Philippines. Int $\mathrm{J}$ Cancer. 2006;118 (1):149-54.

5. DOH. Breast Cancer Medicines Access Program Grand Launch [Online]. 2011 [cited 2012 July]. Available from http://www.doh.gov.ph/content/breast-cancer-medicines-accessprogram-grand-launching.

6. DOH. Implementing Guidelines for the Department of Health (DOH) Medicines Access Program for Early Stage Breast Cancer (Stage I-IIIa). 2010.

7. Dohan D, Schrag D. Using navigators to improve care of underserved patients: current practices and approaches. Cancer. 2005; 104(4):848-55.
8. Del Turco MR, Ponti A, Bick U, et al. Quality indicators in breast cancer care. Eur J Cancer. 2010; 46(13):2344-56.

9. Moher D, Schachter HM, Mamaladze V, et al. Measuring the Quality of Breast Cancer Care in Women. Summary, Evidence Report/Technology Assessment: Number 105. AHRQ Publication Number 04-E030-1 [Online]. September 2004 [cited 2012 July]. Available from http://www.ahrq.gov/clinic/epcsums/brcansum.htm

10. Cheng SH, Wang CJ, Lin JL, et al. Adherence to quality indicators and survival in patients with breast cancer. Med Care. 2009; 47(2):217-25.

11. Weber JJ, Mascarenhas DC, Bellin LS, Raab RE, Wong JH. Patient navigation and the quality of breast cancer care: an analysis of the breast cancer care quality indicators. Ann Surg Oncol. 2012;19(10):32516.

12. Akhtar SS, Nadrah HM. Assessment of the quality of breast cancer care: a single institutional study from Saudi Arabia. Int J Qual Health Care. 2005; 17(4):301-5.

13. Laudico A, Redaniel MT, Mirasol-LumagueMR, et al. Epidemiology and clinicopathology of breast cancer in Metro Manila and Rizal Province, Philippines. Asian Pac J Cancer Prev. 2009; 10(1):167-72.

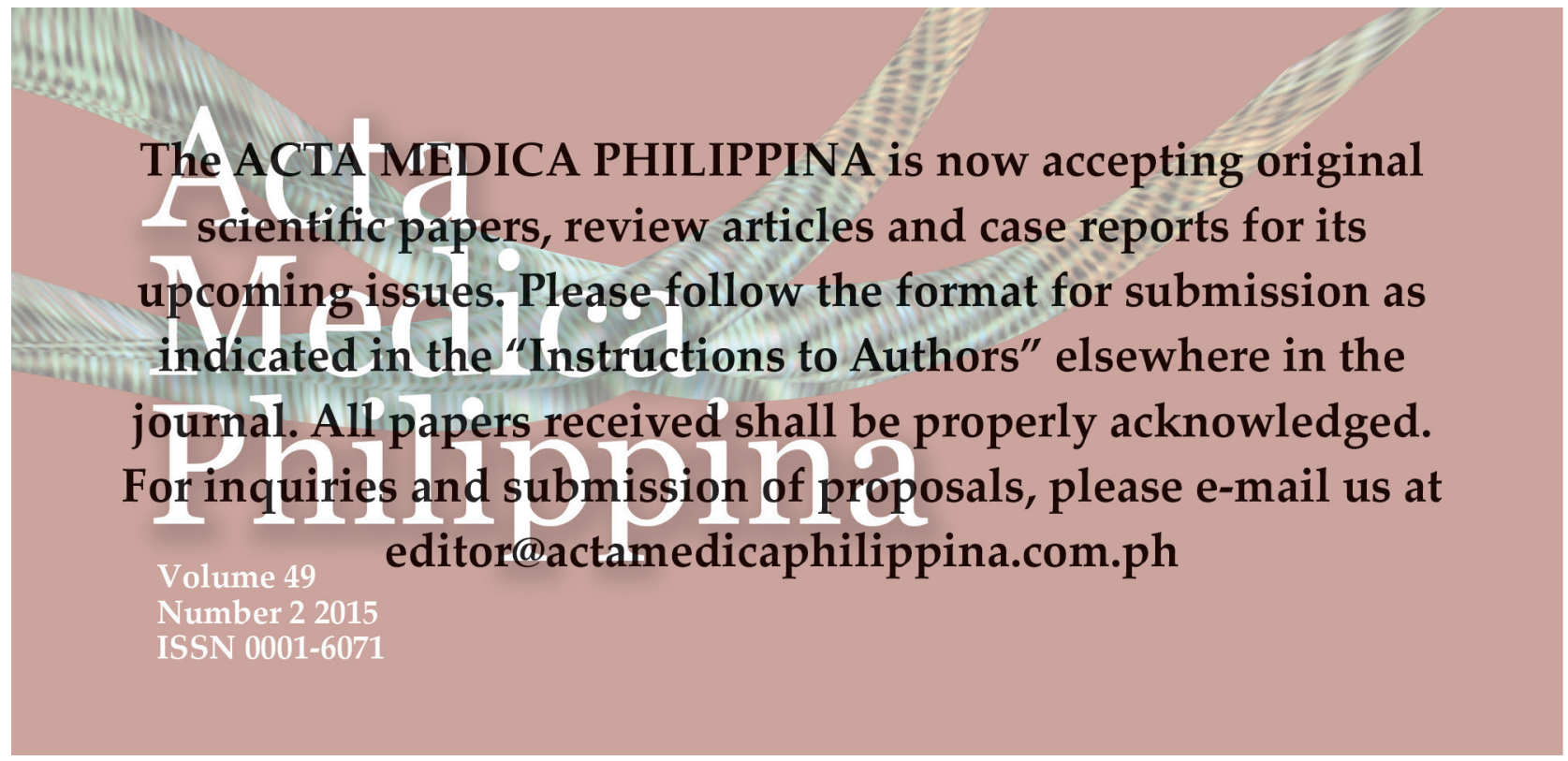

